\title{
LA FEMINIDAD EN EL CINE COLOMBIANO DE 2011 Y 2012
}

\author{
César Oliveros Aya* \\ Carlos Andrés Gómez Ramírez**
}

Fecha de recibido: 17 de febrero de 2013

Fecha de aprobado: 3 de septiembre de 2013

Artículo reflexión.

Forma de citación: Oliveros, C., \& Gómez, C. A. (2013). La feminidad en el cine colombiano de 2011 y 2012. Revista Prolegómenos. Derechos y Valores, 16, 32, 221-234.

\begin{abstract}
Resumen
Este documento aborda tres aspectos: el primero, alude a describir de manera general los diversos escenarios en los cuales, paulatinamente, la mujer ha ido logrando espacios de reconocimiento de su individualidad; el segundo, se centra en la necesidad de profundizar en estudios con perspectiva de género, en especial la tarea que le asiste al Derecho como instrumento de integración y orden social; finalmente, el tercero, aborda una descripción básica de la filmografía colombiana, realizada entre 2011 y 2012 en torno al rol, al lugar dado a la mujer en narraciones que pretenden instaurarse como referentes culturales. Ello conduce a establecer que esta cinematografía ha empezado a recabar en argumentos que promueven la defensa de los derechos femeninos, tratando de hacer visible en términos didácticos, una problemática inserta en la cultura social, política y jurídica.
\end{abstract}

\section{Palabras clave}

Derechos de género, Feminidad, Interpretación, Cine colombiano.

\section{FEMININITY IN COLOMBIAN CINEMA OF 2011 AND 2012}

\begin{abstract}
This paper addresses three aspects: first, referred to generally describe the various scenarios in which, gradually, women have been achieving recognition spaces of their individuality, the second focuses on the need for further studies perspective gender, especially the task that assists the law as an instrument of integration and social order, and finally, third, deals with a basic description of Colombian films, made between 2011 and 2012 about the role, the place given to women in narratives that claim instituted as cultural references. This leads to establish that
\end{abstract}

Abogado, Especialista en Derecho Constitucional; Magister en Docencia e Investigación Universitaria con énfasis en ciencias jurídicas; Docente Investigador de la Universidad Militar Nueva Granada; Coordinador de la línea de investigación "Derecho, Cine y Pedagogía". Correo electrónico: cesar.oliveros@unimilitar.edu.co

** Auxiliar de investigación del grupo de "Derecho Público", línea "Derecho, Cine y Pedagogía" (Facultad de Derecho, UMNG). 
this film has begun to gather in arguments that promote women rights, trying to make visible in educational terms, a problematic culture embedded in social, political and legal.

\title{
Keywords
}

Gender Rights, Feminity, Interpretation, Colombian Movies.

\section{FEMINILIDADE EM CINEMA COLOMBIANA DE 2011 E 2012}

\begin{abstract}
Resumo
Este artigo aborda três aspectos: o primeiro descreve de uma maneira geral os diversos cenários em que as mulheres têm sido atingir gradualmente espaços que reconhecem a sua individualidade, a segunda centra-se na necessidade de novos estudos com uma perspectiva de gênero, especialmente em relação à tarefa que tem direito como um instrumento de integração e de ordem social e, finalmente, o terceiro faz uma descrição básica de filmes colombianos feitos entre 2011 e 2012, em torno do papel, o lugar dado às mulheres em narrativas que fingem ser instituída como referências culturais. Isto leva a estabelecer que esses filmes começassem a coletar argumentos que promovam os direitos das mulheres e está tentando fazer visível, em termos educacionais, uma problemática incorporada nas culturas sociais, políticas e jurídicas.
\end{abstract}

\section{Palavras-chave}

Direitos de gênero, Feminilidade, Interpretação, Filmes colombianos.

\section{INTRODUCCIÓN}

La imagen de la mujer ha cambiado notoria y ostensiblemente en los tiempos actuales, superando de manera progresiva pero ralentizada esa concepción retrógrada de estimarse un ser ligado únicamente a la manifestación de mera sensibilidad, resignación y aptitudes exclusivas para labores domésticas que se traducen en servicio, atención, cuidado de los hijos y del esposo.

La contemporaneidad ha traído nuevos roles, las mujeres se estiman como sujetos de derechos con capacidad para ejercerlos y, sobre todo, exigirlos, amén de conquistas en los campos significativos de la interacción social, económica, incluso política, ahondando en la permanente búsqueda de un reconocimiento que supere las anquilosadas visiones socioculturales que aún estigmatizan la pretendida superioridad del género masculino.
El presente escrito aborda tres aspectos: a) describir, de manera general, los diversos escenarios en los cuales la mujer ha ido obteniendo espacios de reconocimiento de su individualidad; b) la necesidad de profundizar en estudios con perspectiva de género, en especial a la tarea que le asiste al Derecho como instrumento de integración y orden social, y c) aborda una descripción básica de la filmografía colombiana, realizada entre 2011 y 2012 en torno al rol, al lugar dado a la mujer, en narraciones que pretenden instaurarse como referentes culturales.

En el último acápite, el tema se centrará en una somera diagnosis de la sociedad colombiana a través de los personajes femeninos en las películas estrenadas en el país en los dos últimos años (2011 y 2012), que por demás está decir, ha sido el período más prolífico de la cinematografía colombiana en su historia, desde 1986, año en que se llegó a la cifra record de 14 producciones, teniendo en cuenta que en lo que va corrido desde 
el 2011 y hasta la fecha, han sido producidas más de cincuenta películas nacionales (Ministerio de Cultura, Cinematografía. Noviembre 23 de 2012), y sobre el papel del cine como herramienta pedagógica para acercar a la mujer colombiana al conocimiento de sus derechos y los mecanismos para acceder a la justicia como medio de prevención y mitigación de los riesgos a su integridad física, moral, sexual y cultural.

Para tal fin, se han recopilado y analizado una buena porción de estos filmes dentro de los que se encuentran Mamá, tómate la sopa; El escritor de telenovelas; La Captura; Mi gente linda, mi gente bella; Póker; Chocó; La cara oculta; La rabia; 180 segundos; El jefe; Todos tus muertos; Los colores de la montaña; Karen llora en un bus; Locos; Saluda al Diablo de mi parte, y El Páramo.

En consecuencia, la pregunta de investigación es: ¿̇cuál es el aporte que realiza la interpretación de los derechos de género, en la perspectiva del cine colombiano, a la argumentación jurídica y enseñanza del derecho, a partir de la filmografía realizada entre 2011 y 2012 ?

Por consiguiente, la hipótesis planteada es: el cine colombiano sustenta un enfoque socio cultural de los derechos de género que maneja un común denominador con el iberoamericano respecto a la discriminación en el ámbito laboral e intrafamiliar, y permite identificar estructuras argumentativas latentes similares y sistematizar esquemas de interpretación de los derechos humanos.

Corresponde a una investigación de análisis documental, centrada en un enfoque descriptivo y explicativo, con tintes exploratorios en la unificación temática entre Derechos de Género y Cine Iberoamericano.

La técnica de recolección informativa se ha enfocado a fuentes secundarias, esto es, la doctrina existente sobre Derecho Internacional, Constitucional, Teoría del Estado, Filosofía del Derecho, Perspectiva de Género, Hermenéutica y Argumentación Jurídica, Semiótica y Lenguaje Cinematográfico y obras fílmicas de carácter argumental y documental.

\subsection{Escenarios de evolución en el re- conocimiento de derechos para las mujeres}

Son múltiples las facetas que, social y culturalmente, han identificado los roles de interacción y de poder por parte de las mujeres; así las cosas, su reconocimiento paulatino ha ido entronizándose en el devenir cotidiano, en occidente, en la actualidad.

Roles como la maternidad han ido entreviéndose como una opción y no una obligación social, situación no menos controversial en estados confesionales donde la polémica en temas tan álgidos como el aborto - en términos de despenalización- mantiene múltiples posiciones dialógicas e idiosincráticas cuyo debate continúa vigente.

En materia jurídica, los ordenamientos han ido propugnando el reconocimiento de status como cabeza de familia, generando oportunidades de reclamo de derechos y beneficios a partir de créditos, cupos en educación, préstamos, vivienda, prisión domiciliaria en caso de privación de libertad, superando límites de discriminación civil.

El rol político ha ido solidificándose desde 1954, con el ejercicio de su ciudadanía sin mayores ambages, así como la potestad sobre los hijos, la liberalización de la sujeción conyugal desde 1974, lo que ha permitido un mayor equilibrio en comparación con el trasegar histórico.

Empero, la realidad contemporánea muestra que si bien existen avances significativos de gran valor en términos de individualidad, de sujeto y su validación desde la óptica del Derecho y las ciencias sociales, no es condición reconocida para la mayoría de las mujeres latinoamericanas; contrario sensu, huelga la necesidad de atender corresponsablemente como Estado y como Nación ese equilibrio buscado desde hace décadas. 
La feminización del Derecho, como un propósito de desarrollo y evolución social, por supuesto deberá comenzar en el ámbito constitucional, lo cual se erige como uno de los retos de mayor contenido y significado para el verdadero avance del concepto de dignidad en el siglo que corre.

Para la visión feminista, el precitado tema de la ausencia de legalización del aborto, la falta de control al VIH, la inercia interpretativa sobre la cosificación de la mujer, son grandes obstáculos que necesitan superarse, pues aún perviven estancamientos legales que desnivelan las condiciones de vida y estabilidad de una sociedad pretendidamente digna.

Aspectos coyunturales como las costumbres, las tradiciones, los estereotipos socio culturales de la cotidianidad continúan generando ignorancia del Derecho frente a estos temas, haciendo que el discurso humanista, garantista y protector se diluya y se interprete como una utopía permeada por una distorsión de lo moral.

Ante dicho panorama, es menester formular estrategias, soluciones y programas que hagan patente el desarrollo sostenible de la condición del ser humano en aras de soslayar la concepción absurdamente mercantilista del rol de la mujer.

Desde los años ochenta, en Norteamérica y Europa, centros académicos del orden universitario han venido propiciando escenarios para entronizar la idea de «que la pertenencia a un género es una categoría que debe formar parte de los distintos análisis del ámbito social», definición que obliga a tomar medidas urgentes y prontas para correr, de una vez por todas, el velo de ignorancia que envuelve esta problemática.

Valga mencionar el aporte que en Beijing se logró a mediados de los noventa, como un hito en las reivindicaciones de los derechos de género, el hecho de haber logrado incluir en las agendas públicas y políticas de los estados la confirmación de que la problemática femenina radica en el contraste inaceptable entre dignificación del ser humano en su cotidianidad y la posibilidad de un verdadero crecimiento social desde la democracia de los pueblos.

Ello dio lugar a que la Asamblea General de las Naciones Unidas ratificara dichos planteamientos, recomendando «que todo proyecto o programa con miras a obtener respaldo de cualquiera de los organismos internacionales adscritos o vinculados a la ONU, deberá ser elaborado con perspectiva de género, a fin de brindar una visión más exacta sobre la situación en que las mujeres se encuentran y los beneficios que les reporten", según lo plantea Arias (2009, p. 24).

De igual manera, para el Banco Mundial incorporar a las mujeres en el ámbito del desarrollo de los países se entiende como un avance en términos de justicia social y económica. En el informe intitulado La función de la política, estima que si no se invierte en las mujeres, ello puede ser costoso hacia futuro; tener la capacidad de eliminar elementos disgregacionales permite aumentar la productividad, lo que redunda en beneficios sociales y se proyecta hacia la reducción de la pobreza.

Por otro lado, La Comisión de la Condición Jurídica y Social de las Mujeres, que se reunió en New York en el año 2005, cuya función ha sido evaluar resultados provenientes de la ejecución de los acuerdos de la Conferencia Mundial de Beijing, ha destacado el importante proceso de empoderamiento a partir de políticas gubernamentales e institucionales. Dicho concepto novedoso se ha convertido en estandarte para hacer visible el rol femenino, obligando a los estados a nuevas perspectivas de reconocimiento.

Así las cosas, es preciso ahondar en el pasado jurídico de la mujer, las razones de las garantías fundamentales que necesitan replantearse con una visión de género, comprender los aspectos que han validado por siglos los sistemas legales discriminatorios e identificar el sesgo interpretativo de expresiones como igualdad, libertad, justicia y solidaridad que han soslayado la relevancia de la idea de dignidad humana, pues ha sido relativizada. 
Desde ese punto de partida, la definitiva constitucionalización del Derecho será posible, apuntando hacia el planteamiento de políticas públicas que conlleven a impulsar nuevas estrategias que deriven en la readecuación de comportamientos y valores para la oportunidad equilibrada de ambos sexos, menguando así las diferencias que estancan la intencionalidad objetiva de la ciencia jurídica.

La orientación hermenéutica de la temática obliga a la academia a involucrarse en un replanteamiento crítico y equitativo de su legislación, en aras de sensibilizar las dificultades que afrontan las mujeres en contextos actuales, desde la proyección de las facultades de Derecho en la función social que le asiste y justifica su rol.

En el escenario académico se aprende lo teórico pero no se enfatiza en un análisis de género que permita ubicar el problema en perspectiva, un estudio que permita revisar las relaciones de poder, los escenarios de interacción, la demostración del vivir socio político, la capacidad del género femenino para lograr transformaciones valiosas en el entarimado institucional.

Por tales razones, las mujeres aún se supeditan a esquemas androcéntricos con ideales marcadamente patriarcales que las excluyen de la coadyuvancia sustancial requerida para un Estado que intenta ser igualitario y reflexivo.

El propósito del presente escrito es, precisamente, invitar a la reflexión sobre los temas argumentativos de los derechos de género frente a lo validado por las intenciones formales de los ordenamientos jurídicos y lo que es necesario replantear en la vivencia social, como punto de partida para la reflexión crítica desde los mismos escenarios de la formación profesional en Derecho.

Se invita, de entrada, a reconsiderar las interacciones de poder entre hombres y mujeres, con las consiguientes barreras que surgen de la propia cotidianidad, para procurar aproximarse a la visión integral del Derecho al respecto, teniendo en cuenta que este es producto de la vida social, del entendimiento del escenario vivo y no al contrario, pues se halla demostrado de manera suficiente que la formalidad y la rigidez del discurso jurídico no lleva más allá de la erudición, siendo que lo urgente es, de innegablemente, la materialización de las ideas de justicia en términos ponderativos que apliquen a soluciones prontas.

\section{EL ESTUDIO DEL DERECHO CON PERSPECTIVA DE GÉNERO}

Interpretar y argumentar el Derecho desde la asunción de la idea de género implica revalorar la condición humana, el significado de hombre y mujer sin sesgos formales o rigurosamente técnicos. Es atreverse a cuestionar lo insustancial por medio de demostraciones racionales que puedan asimilarse por las mayorías; ello lo convierte en una opción de poder.

Este enfoque permite traslucir las necesidades, intereses y funciones asignadas al sexo femenino, precisa las causas de subvaloración, hace posible una interpretación general del problema y establece los modos de lograr la igualdad de oportunidades en la diferencia.

El Derecho no puede continuar vinculado única y exclusivamente al estudio de normas jurídicas, «sino al proceso de producción de sus respectivas identidades» (Arias, 2009, p. 25), propuesta que se involucra de lleno en el paradigma del realismo jurídico en procura de evaluar contextos interpretativos donde la moderación y la ponderación de los argumentos generen la dialéctica del debate.

Es preciso superar ese sentido de sacralización normativa que ha acompañado tradicionalmente al estudio de lo jurídico; por esa razón, es viable destacar el poder del Derecho como un instrumento de cambio, llamado tecnología de género, comprendiéndolo en tres dimensiones:

- Formal - sustantivo: aludiendo a la necesaria descripción documental de las fuentes, como puntos de partida o aspectos jurídicos que permiten producir comparativamente y a 
través de premisas los postulados argumentativos.

- Estructural: que se centra en la interpretación judicial, hermenéutica de segundo orden, para proveer la decisión jurídica y el análisis contextual.

- Político - cultural: relacionado con el carácter de asunción del derecho subjetivo desde la condición del escenario y rol desempeñado en espacios de poder (Arias, 2009, p. 26).

Se aclara que ninguno de los anteriores panoramas es excluyente, su asunción debe ser simultánea a efecto de manejar un criterio integral de sentido de los textos jurídicos.

Así, podrá asimilarse con mejores resultados la idea de género, entendido como

(...) una construcción cultural de la identidad individual, impuesta a los hombres y mujeres a través de su proceso de socialización; categoría que alude a lo esperado de cada sexo en el plano comportamental e ideológico y que incluye características, conductas, roles, funciones y valoraciones, asignadas a cada uno y que varían en cada sociedad o grupo de acuerdo con factores diferenciadores de las personas que los integran (Arias, 2009, p. 27).

Así, serán las bases biológicas las que otorgan el carácter de género (Arias, 2009, p. 27) y sus repercusiones se dan en los espacios de interacción, tales como la familia, la justicia, el trabajo, el orden económico, etc.

Para Schur (1984), se entiende como un sistema normativo y una extensa red de reglas y sanciones interrelacionadas, a través de las cuales el comportamiento humano (femenino y masculino), es evaluado y controlado. Definición que se sustenta desde el positivismo con marcada referencia al sentido de eficacia, lo que permite inferir una nueva manera de enfocar la temática, pues subvierte la interpretación tradicional desde los inicios de la humanidad.
¿En qué desemboca esta postura? Ineludiblemente en «la reconstrucción de las identidades masculina y femenina, para que los intereses, las necesidades y cualidades de cada sexo ya no sean considerados inmutables, ni de origen biológico, sino producto de la cultura» (Arias, 2009, p. 27).

Analizar las múltiples maneras en que puede operar esta nueva categoría del Derecho implica ahondar en el discurso de pretendida racionalidad que ha manejado la identidad patriarcal en detrimento de la asunción de la mujer, con el ánimo de adaptar el ordenamiento jurídico hacia la intención de equidad jurídica para que ella pueda, a partir de una reconsideración de las fuentes, manifestarse en acciones positivas en todas las facetas del entorno social.

El problema de los derechos de género y, aún más, el contraste entre feminidades y masculinidades continúa siendo uno de los discursos boyantes en la contemporaneidad; un juego de poder sobre el cual se decantan escenarios como la realidad estatal, la comprensión de la historia, la variabilidad prosaica del derecho y la búsqueda infatigable del ser humano para entenderse a sí mismo en términos de complejidad.

Sobre este último aspecto, téngase en cuenta la introspección que la sociedad hace de sí misma desde el ejercicio catártico de las artes, para proyectarla en una asimilación prismática del problema. En dicho panorama, surge el cine como instrumento de memoria, de reflexión, crítica y mimesis de la realidad.

\section{EL CINE COLOMBIANO RECIENTE Y EL PERFIL FEMENINO}

Como todas las manifestaciones artísticas, el cine cumple a cabalidad su labor de retratar la sociedad de la cual se extraen sus argumentos, incluso los que se considera que puedan pertenecer al campo de la ficción.

En una sociedad con la carga histórica de las sociedades latinoamericanas en torno al machismo 
y subvaloración de la mujer, el cine colombiano del último bienio refleja los rezagos de esa historia en cuanto a los roles femeninos descritos en las diferentes producciones cinematográficas.

En este punto de desarrollo del presente trabajo resulta bastante importante recalcar que el papel de la mujer en el cine colombiano no solo se reduce a su aparición como personaje principal o secundario en las producciones nacionales sino también como implementadora e impulsora de producciones que han intentado servir de instrumento de mejoramiento de la situación de la mujer en el mundo, y en el país principalmente, como lo fue la institución feminista Corporación Cine Mujer, fundada en 1978 por Sara Bright y Eulalia Carrizosa, (Arboleda, P. \& Osorio, D. 2013).que produjo diferentes trabajos como $A$ primera vista; Paraíso Artificial; ¿Y su mamá que hace?; Llegaron las Feministas; Carmen Carrascal, y Momentos de un Domingo, con enfoque argumental de corte sexista, que por diferencias internas y dificultades económicas derivadas de la falta de patrocinio, terminó liquidándose en 1999.

A propósito de este tipo de iniciativas lideradas por mujeres, y las cuales tristemente coinciden en la crítica sobre la falta de apoyo tanto estatal como privado para su continuidad, resulta patético descubrir que la participación de la mujer como productora, guionista o directora en los largometrajes de 2011 y 2012 es mínima, tal como se puede verificar en las fichas técnicas de cada una de las producciones utilizadas para la elaboración del presente ensayo, y una de cuyas lecturas puede ser la de que aún en la actualidad esta expresión artística sigue siendo casi de exclusivo acceso al hombre en Colombia, lo cual impone la necesidad de establecer claramente si esta tendencia corresponde al desinterés por parte del género femenino frente a esta faceta artística o a un sesgo impuesto por el género masculino o la sociedad en general.

Es importante aclarar que el análisis del punto anterior se centra en el segmento de largometrajes, dado que en el de cortometrajes la participación femenina a nivel de guión, producción y dirección resulta un poco más representativa, sin llegar tampoco a un equilibrio entre géneros, pero que por ser objeto del presente trabajo el enfoque del cine como herramienta pedagógica en la tarea de aportar a la igualdad de género y la protección de los derechos de la mujer en Colombia, el elemento de la difusión resulta preponderante, siendo de mucho más amplio acceso los primeros que los segundos.

Si bien es cierto que la presencia femenina en el cine nacional de mayor difusión, excepto en la parte actoral, se encuentra reducida al mínimo, también es cierto que existen organizaciones como es el caso del «Club Feminista Cinematria», creado en 2008 en la ciudad de Cali, conformado por cinéfilas, teatreras, comunicadoras, historiadoras y caminantes que se arriesgaron a construir un espacio donde confluyera la diversión con el activismo feminista.

En dicho entorno, se arguyó que:

Decidimos apostarle a construir un espacio donde confluyeran diversión, reflexión, acción, movilización y transformación feminista que han encontrado en el cine una excelente herramienta para movilizar inquietudes entre mujeres, hombres y otras identidades de género que incentivaran pensamientos críticos frente a las realidades de género. Quisimos crear un espacio que permitiera el acercamiento a narrativas audiovisuales de las mujeres y demás identidades de género; descubrir su universo, necesidades, estéticas, denuncias y construcción de memorias. Por otro lado, el movimiento social de mujeres y feminista de la ciudad de Cali ha planteado discusiones importantes alrededor de la necesidad de crear espacios de difusión de las problemáticas de las mujeres. La necesidad de crear espacios en los que lo lúdico, artístico y comunicativo sirva como puente para otras formas de accionar feminista. Recrear el movimiento más allá de las fechas coyunturales y crear un punto de convergencia en el que la imagen sea pretexto para 
diversos diálogos, preguntas y propuestas. En este sentido, quisimos acercar al público a otras experiencias alrededor de la producción audiovisual y de la función social que esta tiene (Cinematría, Cine Club Feminista, Enero 24 de 2013).

Organizaciones de tal naturaleza han partido principalmente de iniciativas exitosas en otras latitudes, dentro de las cuales se destaca la asociación Women in Film and Television International (WIFTI) con presencia relevante en Estados Unidos y el Reino Unido que han encontrado, a nivel latinoamericano, réplicas tan importantes como la mexicana Mujeres en el Cine y la Televisión A.C (MCYTV), creada en el 2002 (Mujeres, Cine y TV, Enero 24 de 2013).

No obstante, es significativo hallar historias contadas por hombres, de personajes como Karen de Karen llora en un bus y Chocó de la producción de su mismo nombre, que retratan historias de vida de mujeres que a pesar de los obstáculos impuestos por una educación que parte desde casa y de una cultura latina históricamente machista, no solo promueven sino que reafirman conductas ejemplares de muchísimas mujeres colombianas, que el cine como instrumento pedagógico tiene la tarea de difundir y ojalá de incitar a replantear la realidad en la lucha constante que se debe librar por una sociedad cada vez más igualitaria en el tema de género.

Corresponde no solo al Estado la promoción $y$ apoyo a este tipo de organizaciones, que propugnan la igualdad de oportunidades para la mujer, y sobre todo de informar y educar a todos los nacionales respecto de sus derechos y las normas en las que se encuentran sustentados, a fin de reducir, y ojalá evitar su vulneración, y también a todos los ciudadanos brindar el apoyo y exigencia a la industria cinematográfica nacional para que dentro de sus producciones se incluyan elementos que enriquezcan día a día la convivencia, el respeto y la tolerancia que merece toda sociedad contemporánea en la cual no puede haber cabida para la segregación de ningún tipo entre la diversidad de seres humanos.
Es así como a lo largo de estas producciones cinematográficas, estrenadas entre los dos años inmediatamente anteriores, se advierte una gran cantidad de personajes femeninos que resultan determinantes para el desarrollo de cada una de ellas, plasmando de manera muy certera el papel que juega en la sociedad colombiana actual la mujer con los defectos, virtudes y características propias de las diferentes clases sociales, grados de escolaridad e historias particulares que, a través de estos trabajos cinematográficos, nos son narradas y extraídas tanto del imaginario particular del autor como del colectivo $y$, por supuesto, de la realidad social.

Una de las más llamativas facetas de la mujer colombiana que se ha querido imprimir en gran parte de los trabajos fílmicos que han sido utilizados para la presente investigación, es el de sujeto determinante de las conductas y decisiones de los hombres, bien sean sus parejas sentimentales o tengan vínculo familiar estrecho con estos.

Es así como se detalla que en varias de las películas cuyo eje central es una historia romántica, (sirvan de ejemplo El Jefe; Mamá, tomate la sopa; Locos; En coma e incluso La Captura), el rumbo de cada historia ha sido determinado, de manera premeditada o como consecuencia indirecta, por la decisión tomada por el hombre que busca a cualquier precio conseguir o conservar el amor de la protagonista para sí.

Esta faceta convierte a la mujer colombiana en la motivación primordial u objetivo último del hombre que, obedeciendo al adagio «el fin justifica los medios» la convierte en el móvil de peripecias divertidas y arriesgadas, así como también de delitos que resultan muy bien plasmados en producciones como $\mathrm{El}$ jefe y Locos.

Otra faceta de gran importancia es la que describe sus cualidades humanas resaltadas en la mayoría de las ocasiones por el estrato humilde del que surgen la mayoría de las protagonistas, como son los casos de Fabiana en la Cara Oculta, Miriam en Los Colores de la Montaña, Chocó en Chocó o Rosa en Rabia y que reconocen las 
virtudes, capacidad de sacrificio, solidaridad y valentía de la mujer colombiana.

Uno de los aspectos neurálgicos en el presente análisis, y que será reiterativo de manera más amplia en párrafos posteriores, será el de la mujer maltratada tanto por la sociedad en general y por el hombre en particular, como se puede apreciar de la manera más desgarradora en El Páramo, película en la cual una supuesta bruja, mujer que no puede darse a entender de manera verbal y con un historial de maltrato y tortura, continúa siendo maltratada, violada y torturada bajo la sospecha de que es guerrillera y posteriormente hechicera, situación no alejada de la realidad si se tiene en cuenta el reciente caso de violencia derivado de la intolerancia, acaecido en Santa Bárbara (Antioquia), en el cual una mujer fue asesinada e incinerada por presuntas actividades de hechicería (El Tiempo, 2012a). Otro rasgo prevalente de la mujer colombiana, presente en cada una de los filmes nacionales, independiente de si los medios utilizados para ello son legales, ilegales, legítimos o no, es el ser emprendedora y perseverante en cuanto a la consecución de sus metas, principalmente cuando se trata de sacar adelante a su familia; es así como este paradigma de mujer se encuentra plasmado en Cristina en Mamá, tómate la sopa, Chocó en Chocó y Camila en Póker por nombrar solo tres de tantos roles femeninos con estas características.

De gran consideración resulta el análisis de lo que la cinematografía colombiana en 2011 y 2012 retrata respecto de la participación femenina en los diferentes ámbitos de la vida nacional. Para orientar una evaluación de la fidelidad o no de esta forma de representación a través del cine, es necesario acudir a la historia relativa a los avances de dicha participación en diferentes aspectos de la vida colombiana. Es así como huelga situarse en una fecha hito en el logro de reconocimiento de igualdad frente al hombre, acontecida en el año 1957 por medio del plebiscito que otorgó igualdad de derechos democráticos entre géneros, siendo Colombia uno de los últimos países de Latinoamérica que prosperó en dicho logro.
Hasta la década de los cuarenta del siglo pasado, la mujer colombiana no tenía su propia representación, pues ella recaía primero en el padre $y$, posteriormente, en el esposo; esto significaba que las mujeres no tenían derecho siquiera a administrar sus bienes. Durante las coyunturas de las guerras mundiales, especialmente de la segunda, por medio de los avances industriales y tecnológicos se propició en nuestro país la educación igualitaria en cuanto a materias entre hombres y mujeres y es, sin duda, este avance en el sector educativo el que planta las semillas más esperanzadoras para el camino de la igualdad de géneros en Colombia, dando un paso fundamental con la Constitución del 1991, y que a la fecha aún se viene desarrollando.

El aspecto educativo, según la descripción del cine colombiano durante los años 2011 y 2012, sigue jugando un papel fundamental en la igualdad de géneros, lo cual se puede considerar que es fiel copia de la situación actual como puede apreciarse claramente en las diferencias que establecen varios personajes de las películas referidas como son, por un lado la jefe (Marcela Carvajal) de Vigo Larson en Mi gente linda, mi gente bella quien es una mujer ejecutiva con alto grado de escolaridad y cuya educación le permitió escalar hasta la posición más importante de la empresa para la que trabaja y también Piedad, Caridad y Fanny de Postales Colombianas quienes son mujeres igualmente profesionales que han llegado a una buena posición gracias a ello.

Por otro lado, tómese por ejemplo a Miriam, esposa de Ernesto, en Los colores de la monta$\tilde{n} a$, quien es una mujer de estrato humilde, con una escolaridad que difícilmente haya llegado a la secundaria y cuyas situaciones particulares permiten inferir a partir de la cinta, que no le dieron opciones más allá que la de unirse en matrimonio a un campesino que la agrede físicamente y cuyas decisiones son las únicas que se acatan en su hogar; otras dos mujeres de similares características resultan encarnadas en la esposa de Salvador en Todos tus muertos, quien en este caso es víctima constante de abusos sexuales por parte de su esposo, y de la misma 
manera encontramos a Chocó de la película homónima quien sufre también de continuos maltratos físicos, sexuales y morales por parte de Everlides, su esposo.

A pesar de los muchos ejemplos de superación de mujeres de bajos recursos económicos que lograron posicionarse en importantes escaños de la vida política, económica y cultural de nuestro país, el rezago en el protagonismo de la mujer en todos los niveles aún es evidente; muestra de esto es que en las últimas elecciones legislativas las mujeres alcanzaron tan solo el $14 \%$ de participación en el Congreso con 37 electas frente a 230 hombres congresistas (Barbosa, 2012).

Un punto, igualmente desarrollado por los productores y guionistas del cine colombiano, es el de algunas mujeres, como es el caso de Angélica en 180 segundos, quien es un personaje de aproximadamente 25 años de edad, con conocimientos en informática y telecomunicaciones, quien a falta de oportunidades a nivel laboral para la consecución de recursos para continuar su educación formal, opta por actividades delictivas para subsanar las falencias económicas que le impiden el acceso a una universidad.

Este tipo de desigualdades no son particulares de Colombia; de hecho, según el Banco Mundial en su «Informe sobre el desarrollo mundial: igualdad de género y desarrollo. 2012», la brecha entre géneros dada, por ejemplo en mejores posiciones de los hombres a nivel laboral respecto de las mujeres $e$ incluso en las diferencias salariales entre ambos géneros cuando ostentan la misma posición o cargo, son $20 \%$ menores en nuestro país que en la media latinoamericana, hecho que si bien nos indica que vamos por buen camino, también nos permite deducir que las producciones cinematográficas colombianas de estos dos últimos años, analizadas en contexto, representan muy bien la importancia del papel de la educación como política pública de Estado para aminorar cada vez más esa brecha.

La educación cobra importancia dentro de este análisis en la medida en que los patrones cultu- rales y sociales por los cuales se rigen la mayoría de los pueblos latinoamericanos son fuente de discriminación y subordinación de las mujeres, particularmente en Colombia, y que, consecuencialmente, derivan en hechos de violencia en contra de ellas a pesar de legislaciones tan proteccionistas como la que actualmente rige en el país, principalmente contenida en la Ley 1257 de 2008, pero que lamentablemente por obstáculos denominados técnicamente como "pobreza legal» $\mathrm{O}$ «desconocimiento de derechos» por parte de la población femenina, la mayoría de las veces quedan en letra muerta (Casmujer, Noviembre 21 de 2012).

En aras de solventar esta situación, de manera paralela a la implementación de mecanismos pedagógicos que pongan en conocimiento de las mujeres colombianas, tanto las normas sustantivas como los mecanismos de acceso a la justicia, actualmente se encuentra en curso de expedición una ley que obliga a las autoridades a investigar de oficio los hechos constitutivos de agresión a mujeres, así como también el eliminar de la categoría de querellables y desistibles este tipo de conductas punibles (El Tiempo, Noviembre 23 de 2012).

Expresiones artísticas colombianas como el cine ponen en evidencia situaciones de maltrato $y$ violencia contra la mujer, sirviendo de instrumento pedagógico para que ellas se acerquen un poco más al conocimiento de sus derechos y de los instrumentos jurídicos de los que pueden valerse para prevenir, evitar y mitigar los riesgos a su integridad física, moral, cultural y sexual.

A propósito del cine y la pedagogía, dice la doctora Carmen Rodríguez Fuentes que

El cine puede ser un recurso pedagógico, es decir, que sirva para educar o enseñar. El carácter narrativo del cine facilita transmitir conocimientos, siendo una alternativa cuando otras metodologías no han tenido éxito. Por ejemplo, materias como la Historia Universal, que son de naturaleza narrativa, encuentran en el cine un fiel aliado (Fuentes, 2012). 
Si bien el texto citado corresponde a un documento en el que la doctora Fuentes Rodríguez se refiere a la utilización del cine como método pedagógico para la enseñanza de Historia, puede decirse también que por la similitud de contenidos en cuanto a su complejidad entre historia y derecho, dicho postulado tiene perfecta aplicación también a este último campo, ya que «en la sociedad actual, en la que los límites entre cultura y entretenimiento cada vez están más desdibujados, el cine es más valorado porque el ocio nos puede llevar al conocimiento» (Fuentes, 2012).

Es claro que en un país como Colombia, en el cual se cuenta a septiembre de 2012 con más de 1.600.000 personas en condición de analfabetismo (El Espectador, Septiembre 9 de 2011), pero que a su vez cuenta con un cubrimiento del $100 \%$ en cuanto a señal de televisión satelital que puede ser accedida de manera gratuita (Roster Software, Enero 23 de 2012), y sumado a esto que no solo las mujeres de bajos niveles educativos son las que sufren las consecuencias del desconocimiento de sus derechos, la posibilidad que se abre paso de que el cine, como herramienta pedagógica, juegue un papel de gran relevancia en las dinámicas de nuestra sociedad actual, resulta bastante evidente y necesario, si se utilizan para su difusión medios como el televisivo que cuenta con los recursos para ser accedido sin costo por una gran porción de la población. Este tema debería contemplarse en el orden del día de quienes definen las políticas estatales.

Razones bastante válidas en cuanto a la utilidad del cine como estrategia pedagógica directamente relacionadas a la formación en el Derecho las menciona Pérez Triviño (Noviembre 23 de 2012) según las cuales la persona a la que se intenta formar se acercará de manera más interesante y amable al tema jurídico expuesto, ya que estará más motivado en el análisis de la cuestión que si estuviese enfrentado a una explicación teórica en un aula de clase, pues para gran parte de la población esta metodología no le permite captar el contexto, su relevancia o sus consecuencias prácticas.
Pasando a otro aspecto relacionado con el tema jurídico en el campo del derecho penal general, contenido principalmente en la normatividad legal sustancial, es este campo en el cual el cierre de la brecha entre géneros ha avanzado más dada la eliminación en la casi la totalidad de los tipos penales de la diferenciación entre hombres y mujeres. Es entonces cuando se debe recordar que hasta el año 1936 existía, en este ordenamiento jurídico, el delito de adulterio, el cual solo era imputable a la esposa y cuya pena era, incluso, impuesta no por el juez sino por el propio esposo teniendo como única limitante no exceder de cuatro años.

Los tipos penales como el anteriormente mencionado lesionaban, de manera inconcebible, desde la perspectiva actual, los principios de igualdad frente a la ley de hombres y mujeres al imponer solo a la mujer la pena por una conducta que podía ser desplegada por cualquiera de los cónyuges, de hecho, con más ocurrencia por parte del cónyuge masculino que el femenino.

Las implicaciones que tendría un artículo como este, en nuestro actual Código Penal, aplicadas a los personajes femeninos de las películas objeto del presente ensayo, dejaría tras las rejas, por ejemplo a Karen, de Karen llora en un bus, personaje que resalta las mejores virtudes y características de nuestras mujeres y a quien resulta bastante fácil admirar por su lucha y deseos de superación frente a un matrimonio que la hace infeliz, al no poder desarrollarse como ser integral enfrentándose siempre a la sentencia de su esposo quien tiene por seguro que nunca cumplirá sus amenazas de dejarlo «¿de qué vas a vivir si no sabes hacer nada?», y a la encantadora y admirable Chocó de la película de su mismo nombre, y en cambio convertiría casi en «héroes» indemnes jurídicamente a personajes como Osorio de El Jefe y al Teniente Rudas de La Captura, situación que, aún en la actualidad, muestra sus rezagos al ser claramente más aceptada cultural y socialmente la infidelidad del hombre que la de la mujer.

De esta manera, se encuentra que, como expresión artística que conjuga el teatro y la literatura 
o crónica, llevados a la pantalla mediante el avance tecnológico de la fotografía, el cine colombiano cumple cabalmente con su cometido de reflejar la realidad de nuestra idiosincrasia, costumbres, virtudes, defectos, con drama o buen humor o una muy bien lograda mezcla de ambos, dando lugar a repensar y reingeniar estrategias para la búsqueda de una sociedad cada vez más igualitaria, con más oportunidades y más reconocimiento de la mujer colombiana.

Por lo tanto, su aporte como medio de difusión de esta realidad social aunado a mecanismos de pedagogía que acerquen más, no sólo a la mujer sino a la generalidad de individuos que componen el Estado, pueden lograr la disminución en los índices de vulneración y vulnerabilidad de los derechos femeninos en Colombia.

\section{CONCLUSIONES}

Históricamente la brecha existente entre sexos en Colombia ha mostrado un gran avance a partir del último cuarto de siglo con la aparición de fuertes movimientos sexistas que buscaron, mediante expresiones artísticas como el de la cinematografía, difundir las vivencias, desventajas, amenazas, fortalezas y vulneración de derechos de la mujer; derechos que hasta mediados del siglo XX no existían o eran considerados letra muerta tanto por su desconocimiento como por disposiciones jurídicas que dejaban en condición de inferioridad al sexo femenino sometido a la tutela del hombre, catalogándose incluso de «incapaz».

No obstante ese avance, la vulneración de los derechos de la mujer, aún hoy a comienzos del siglo XXI, parece no detenerse, bien sea por la falta de educación, al respecto de los instrumentos para hacerlos efectivos o porque la masificación y cubrimiento de los medios se acercan a evidenciarla en sus niveles reales.

El desarrollo en Colombia de los derechos femeninos ha ido avanzando de la mano tanto de agentes externos como internos, dentro de los cuales se ve una clara y fuerte injerencia de los medios de comunicación y, particularmente, de las mujeres ligadas a estos medios, dentro de las cuales se evidencian organizaciones de corte feminista que luchan visiblemente desde el año 1978 con logros importantes a partir de la producción cinematográfica de films que buscaban plasmar tanto los reproches a una sociedad rezagada en la lucha de igualdad de géneros, como de grandes logros de mujeres que buscan convertirse en modelos a seguir, enalteciendo sus innegables virtudes.

La tendencia gubernativa en las últimas décadas ha demostrado el interés por implementar, desde lo institucional, mecanismos de protección y fomento de los derechos de la mujer, pero omiten el apoyo a aquellas organizaciones cuya iniciativa parte de las mismas mujeres $y$, por tanto, obedecen a necesidades más concretas. Un avance importante puede tenerse si se conjugan los esfuerzos institucionales y de estas bases que conocen mucho más a fondo su propia problemática, debilidades, fortalezas, carencias y oportunidades.

Existen ejemplos concretos y una doctrina bastante amplia en lo referente al importante aporte del cine en la labor de difundir tanto la problemática de la mujer en sociedades con rezagos machistas como de los mecanismos de protección a sus derechos.

\section{REFERENCIAS}

Acosta, A. \& Hinestroza, J. H. (2012). Chocó [película]. Colombia.

Arbeláez, C. C. (2011). Los colores de la montaña [película]. Colombia y Panamá.

Arias, M. (2009). El Derecho, los Derechos Humanos y las políticas públicas, con perspectiva de género. Bogotá: Impresol Ediciones.

Baiz, A. y Ruiz-Zorrilla, H. K. (2011). La cara oculta [película]. España y Colombia. 
Barbosa, F. (2011). Observatorio de Humanas: las mujeres en los medios. Extraído desde http://www. humanas.org.co/archivos/Articulo_Mujeres_y_ congreso.pdf

Cabal, L. \& Motta, C. (Comp.). (2006). Más allá del Derecho, Justicia y Género en América Latina. Bogotá: Siglo del Hombre.

Casmujer. (2012). Violencia contra las mujeres. Extraído en Noviembre 21 de 2012, desde http:// www.casmujer.org/INFO-1.\%20CIDH

Cinematría. (2013). Cine Club Feminista, Acerca de nosotras. Extraído en Enero 24 de 2013 desde http://cinematria.blogspot.com/p/acercade-nosotras.html

El Espectador. (2011, Septiembre 9). Analfabetismo en Colombia. Extraído en Noviembre 23 de 2012, desde http://www.elespectador. com/impreso/vivir/articulo-297906-colombia1672000-analfabetasabetismo

El Tiempo. (2012a). Sin título. Extraído en Septiembre 3 de 2012, de http://www.eltiempo. com/colombia/medellin/ARTICULO-WEB-NEW_ NOTA_INTERIOR-12191850.html>,

El Tiempo. (2012b). Sin título. Extraído en Junio 12 de 2012. http://www.eltiempo.com/ politica/ARTICULO-WEB-NEW_NOTA_INTERIOR-11938004.htm

El Tiempo. (2012c). Sin título. Extraído el 23 de Noviembre de 2012, desde http://www.eltiempo. com/colombia/medellin/ARTICULO-WEB-NEW_ NOTA_INTERIOR-12191850.html).

Escallón, J. (2011). El jefe [película]. Colombia.

Fuentes, C. (2012). El cine como recurso pedagógico. Extraído en Noviembre 23 de 2012, desde www.cervantesvirtual.com/.../el-cine-comorecurso-pedaggico-0/

García, D. A. (2011). El escritor de telenovelas [película].
García, D. A. (2012). La Captura [película]. Colombia.

García, D. A.; Ortíz, J.; \& Rodríguez, H. (2012). Mi gente linda, mi gente bella [película]. Colombia.

Giraldo, A. (2012). 180 segundos [película]. Colombia.

Ministerio de Cultura. (2012, Abril 8). Cinematografía, Películas Colombianas. Extraído de http:// www.mincultura.gov.co/?idcategoria $=35443$,

Ministerio de Cultura. (n.d.). Películas Colombianas. Extraído Noviembre 23 de 2012, desde http:// www.mincultura.gov.co/?idcategoria $=35443$ )

Mujeres, Cine y TV. (2013). Cine y feminidad. Extraído en Enero 24 de 2013, desde http://www. mujerescineytv.org/?page_id $=50$

Orozco, C. E. (2011). Saluda al Diablo de mi parte [película]. Colombia.

Pérez, J. L. (n.d.). Cine y Derecho, Aplicaciones Docentes. Extraído en Enero 23 de 2012, desde https://www.google.com.co/\#hl=es\&tbo=d\&ou tput $=$ search\&sclient $=$ psy-ab\&q $=$ cine $+y+$ dere cho\&oq $=$ cine $+y+$ derecho\&gs $1=$ hp.3..017j0i3 013.1559.8704.1.8953.28.18.7.3.4.0.285.3661 .0j10j8.18.0...0.0...1c.1.b281VdflgtA\&psj=1\&b av $=$ on.2,or.r_gc.r_pw.r_qf.\&fp $=c 4 b 01645 \mathrm{fOa} 4$ $\mathrm{b} 457 \& \mathrm{bpcl}=38897761 \& \mathrm{biw}=1024 \& \mathrm{bih}=499$

Pinzón, G. y Trompetero, H. (2011). Locos [película]. Colombia.

Ribero, M. (2011). Mamá, tómate la sopa [película]. Colombia.

Ríos, P. A. \& Gómez, D. O. (2002). La presencia de la mujer en el cine colombiano. Medellín: Universidad Pontificia Bolivariana.

Rojas, G. (2011). Karen llora en un bus [película]. Colombia. 
Roster Software. (2012). Televisión satelital gratuita. Extraído en Enero 23 de 2012, de http:// www.rostersoftware.com/tv/Article4.html.

Torres, A. \& Moreno, C. (2011). Todos tus muertos [película]. Colombia.

Universidad Pontificia Bolivariana. (n.d.). Tesis mujer en cine colombiano. Extraído en Enero 24 de 2013, desde http://eav.upb.edu.co/banco/sites/ default/files/files/Tesismujercinecolombiano.pdf)
Valencia, J. S. (2011). Póker [película]. Colombia.

Vianello, M. \& Caramazza, E. (2002). Género, espacio y poder: para una crítica de las Ciencias Políticas. Madrid: Cátedra, Universidad de Valencia e Instituto de la Mujer.

Vivanco, D. \& Osorio, Jaime. (2012). El Páramo [película]. Colombia, Argentina y España. 